\title{
KÜRESELLEȘME VE YERELLİK BAĞLAMINDA GÜNÜMÜZ TÜRK SİNEMASI
}

\author{
Dr. Okan ORMANLI \\ İstanbul Kültür Üniversitesi, Sanat ve Tasarım Fakültesi, İstanbul, Türkiye \\ o.ormanli@iku.edu.tr
}

\begin{abstract}
The Art of Cinema, which has a past of more than a century long, is frequently discussed in terms of globalization and localization. Cinema started in Europe (France) but became a worldwide phenomenon due to the US (Hollywood). And today Hollywood, which generally represents the American cinema industry and commercial cinema, is the leader in terms of spectator and profits with billions of dollars. It constantly tries to enter every corner of the world to show / sell American movies after the rise of the globalization and sometimes makes concessions in terms of national values. Turkish cinema which is on the way to create a renaissance after the fall of Yeşilçam in terms increasing number of films and spectators by beating Hollywood's big productions has the most percentage with its local admissions in Europe. Turkish cinema is successful at home and receives international awards almost every year but not as widespread comparing with other successful European cinemas. In this study, the reasons for the failure of Turkish, which has remained local yet also aims at taking on a more global nature, will be analyzed.
\end{abstract}

Keywords: Globalization, cinema industry, Turkish cinema.

\section{GİRIŞ}

Küreselleşme teknolojik imkanların çoğalmasıyla ekonomik, ticari, sosyo-kültürel anlamdaki bir takım değişim ve dönüşümlerle günümüzde sıkça tartışılan bir olgu haline geldi. $\mathrm{Bu}$ bağlamda dünyanın hemen hemen her ülkesinde yaşamın neredeyse tüm alanlarına hakim olmaya başlayan küreselleşme hakkında son zamanlarda çok sayıda bilimsel çalışma yapılmış ve sanatsal eserler meydana getirilmiştir.

Küreselleşme ilgili çalışmalarda genellikle yerel ve ulusal değerlerin yok olma tehlikesi altında olduğu, vaadedilen çok seslilik yerine tek tipleşme ve tek seslilik gibi sakıncalara değinilmektedir. Günümüzde geniş kitleleri etkileyen ve en güçlü sanat dallarından biri olan sinema milyar dolarlarla ifade edilen ticari getirisi ile dünyanın en önemli ticari faaliyet alanlarından biridir. Bu nedenle küresel sermaye, çok uluslu şirketler daha bir çok kurum ve kuruluş sinema ile yakından ilgilenmektedir.

Sinemanın ticari boyutu kadar kültürel boyutu da o denli önemlidir. Sinema sanatı üzerine son zamanlarda nicel çalışmaların yanı sıra niteliksel ve ideolojik çalışmalar da giderek çoğalmaktadır. Bu çalışmaların baş rolünde sinema alanında neredeyse dünyada tek hakim olan Hollywood ve onun başarıları, etkileri, faydası, zararları ve benzeri konular akademik olarak ele alınmaktadır. Bir çok ülke kendi ulusal sinemalarını korumak için ticari ve yasal tedbirler almaktadır.

Türk sineması ise son 20 yıldaki Hollywood egemenliğini film sayısında olmasa da yerli film izleyicisi anlamında kırmıştır. Bir çok Türk filmi uluslararası alanda prestijli ödüller almakta, uluslararası festivallere katılmakta ve ortak yapımlara ya da büyük bütçeli fillmlere eve sahipliği yapmaktadır. Bu bağlamda Türk sineması son zamanlarda dünya sinema piyasasının, sinemacıların ve eleştirmenlerin dikkatini çeker bir konuma gelmiştir. 


\section{DÜNYA SİNEMA ENDÜSTRİSI}

Dünya sinema sektörü bir çok kaynakta; izleyiciler, film kiralayıcılar, ev video gelirleri, online film kiralama hizmetleri ve internetten edinilen film bedelleri olarak nitelendirilmektedir. Ayrıca sinema sektörü genel olarak; Kuzey Amerika, EMEA (Avrupa, Ortadoğu, Afrika), Asya Pasifik ve Latin Amerika olarak dört bölgeye ayrılmaktadır. Yaklaşık 90 milyar dolarlık global sektör büyüklüğünün neredeyse yarısı Kuzey Amerika bölgesinde bulunmaktadır. EMEA yaklaşık 27-28 milyar dolarla ikinci sırada yer almaktadır. Asya Pasifik ise yaklaşık 20 milyar dolarlık pay ile üçüncü sırada yer almaktadır. Latin Amerika ortalama 2-3 milyar dolarla zincirin en zayıf halkasıdır. Uzmanların ön görüsüne göre global sinema sektörü 2013 yılında giderek büyüyerek 100 milyar dolarlık bir güce ulaşacaktır. Kuzey Amerika yaklaşık 45 milyar dolarla lider konumunu devam ettirirken diğer bölgelerde de benzer oranda artışların olacağı tahmin edilmektedir (Çelik, s.247-248).

Sinema sektöründe gişe gelirleri dağılımında önce dağıtımcı masrafları karşılanır. Dağıtımcı payı ABD içinde \%30, uluslararası pazarda \%40-45. Blockbuster denilen büyük bütçeli filmlerde dağıtımcı payı 2-4 hafta içinde \%70'lere ulaşabilmektedir. Avrupa'da 1990'lar sonu ve 2000'lerin başında kar marjı film yapımında neredeyse sıfır olmuştur. Dağıtımda ise kar payı yaklaşık \%3'tür (Erus,2007,s.6). Günümüzde ABD'de filmlerin \%80-90'ı büyük stüdyolarca dağıtılmaktadır. Çeşitli yöntemlerle stüdyolar filmlerini seyirciye ulaştırırken, büyük gişe getirisi beklenen filmlerle birlikte daha az popüler filmler de dağıtımcıya dayatılmaktadır (Erus, 2007,s.7).

Günümüzde başlıca Hollywood stüdyoları Warner Bros, Fox, Columbia Tri-Star kendi başlarına Paramount ve Universal ise UIP çatısı altında uluslararası dağıtım şirketlerine sahiptir. Bu şirketler ve temsilcileri dünyanın hemen hemen her ülkesinde film dağıtımını kontrol etmektedir. Örnek vermek gerekirse, 1980'lerde Güney Kore'de Türkiye'ye benzer şekilde yasal değişikliklerle Hollywood şirketleri filmlerini doğrudan dağıtıma başlamış piyasa gelirlerini $\% 80$ 'i bu şirketlere geçmiştir. Son zamanlarda tüm dünyada olduğu gibi Güney Kore'de de pazar Hollywood filmlerine belirli bir doygunluk göstermiş ve Hollywood tarzı yerel filmler ön plana çıkmıştır (Erus, 2007,s.9).

1960'lar ve 1970'lerde Hollywood sinemasındaki yapımcı egemenliğine karşın yaratıcı ve bağımsız projelerede yer verilmiştir. Hollywood stüdyoları yönetmenlerin sanatsal heveslerini tatmin etmeleri amacıyla onların isteklerine ve taleplerine ve denemelerine izin vermiştir. Ancak bazı başarısız denemeler sonrası (geniş kitlelere hitap edecek sanatsal filmlerin başarısız olması) artık yönetmenlerin ilahlaştırıldığı ve yapımcının kötülendiği dönem sona ermiştir. 1980'lerde bu bağlamda blockbuster denilen ve ortalama 100 milyon dolar bütçeye sahip dev prodüksiyonlar dönemi başladı. Bu filmlerin başarılı olması için en az 2-3 katı gişe geliri gerekmektedir. $\mathrm{Bu}$ nedenle filmler genelde Noel ya da yaz tatili dönemlerinde gösterilmektedir. Dolaylı reklamlarla satılan ürünlerin miktarı da önemlidir. Oyuncaklar, bilgisayar oyunları, DVD'ler ve devam filmleri vb. Böylece film, gösterimden kalksa bile getirisi devam etmektedir. Diğer özellikleri seyirciye yaşattıkları deneyim. Gerçeküstü veya hiper gerçeklik gibi terimlerle nitelendirilmektedir. Bu filmleri çeken yönetmenlerin başarısı ilk filmler üzerinden kendini pazarlayabilme becerisi kısacası gişe başarısı gerekmektedir. Böylece biçim, anlatının önüne geçmeye başlamıştır. Hareketli özel efektlere dayalı fantastik apolitik, gençlere dayalı ve karakterlerden çok konu odaklı filmler giderek artmıştır (Erensoy, 2012, s.57-61).

Hollywood blockbuster filmlerinin toplam gişesinin 2/3'ü uluslararası pazarlardan gelmektedir. Bazı animasyonlar çeşitli ülkelerde dublaj ve şakalarla yerelleştirilmektedir. Hollywood stüdyoları uluslararası alanda daha çok kişiye ulaşmak için proje üretmektedirler. Böylece dil ve kültür farkı sorunu aşılmaktadır. Ayrıca starların kim olduğu değil nereli olduğu önem kazanmaktadır. Bu bağlamda uluslarası oyuncu kadrosuna sahip "Karayip Korsanları" ile "Rio" ve "Buz Devri" belirli bir kültüre mensup olmayarak başarılı oldular. 
Bilhassa "Rio" ve "Buz Devri" gibi filmlere dublaj yapılarak yerelleştirme imkanları da vardır. Hollywood epik yapıdaki macera filmlerinin ve süperkahraman yapımlarının yabancı izleyiciler için cazip türler olduğunun bilincindedirler. Bunun yanı sıra western ve bilimkurgunun birleştirildiği "Kovboylar ve Uzaylılar" gibi örnekler de söz konusudur (Whipp, 2011a).

Pixar'ın animasyon filmi “ Arabalar 2" dünya çapında 44 dilde gösterilmiştir. Her ülkede filmde ana karakterin seslendirilmesi sorun olmuştur. Ortak vokal bir kültür olmaması bir ABD animasyonundaki özel bir karakteri anlaşılmaz kılabiliyordu. $\mathrm{Bu}$ nedenle ülkelere çözümler üretmek için çaba sarfedilmektedir. Çeviride ya da filmin anlaşılmasında gerekli olan ve sessiz dönemden beri kullanılmakta olan altyazı da uluslararası alanda önem kazanmaktadır. Bunun yanı sıra, altyazı okumaktan hoşlanmayanlar ya da okur yazar olmayanlar için de 1930'lardan itibaren dünya sinemasında bir çok filme dublaj yapılmıştır. Küresel rekabetin bir parçası olan bu süreçte doğru çeviri de ayrıca önem kazanmaktadır (Whipp, 2011b).

“Görevimiz Tehlike”, “Transformers”, “Tintin” gibi 2012'nin pahalı yapımları uluslarası alanda büyük başarı kazanmışlardır. Spielberg'in “Tintin” adlı filmi daha ABD'de gösterilmeden 2 ay önce Avrupa'da gösterime girmiş ve 300 milyon dolar gişe geliri elde etmiştir. "Görevimiz Tehlike" Rusya, Hindistan ve Birleşik Arap Emirlikleri gibi uluslararası mekanlarda çevrilmiş ve film premiyeri Dubai' de gerçekleştirilmiştir. Bu bağlamda Amerikan edebiyatının önemli eserleri fazla Amerikanvari bulunarak uluslararası seyircinin ilgisini çekmemektedir. Bunların yanı sıra Hollywood filmleri Amerikan değerlerini fazlaca empoze etmeden ancak ABD malı etiketiyle ticari başarı ve teknik kalite garantisi vermektedir. ABD'de sinema okulları, sinema dernekleri, meslek kuruluşlarından yetenek ajanslarına kadar büyük bir kurumsallaşma söz konusudur. Hollywood'un ticari filmleri belli başlı Amerikan değerlerine daha az değinirken, stilleri ve teknik üstünlükleriyle küresel anlamda bir çok yetenekli sinemacıyı bir araya getirmektedir. Ve farklı kültür ve ülkelerden sinemacı ABD'de ABD değerlerine uygun filmler çekmektedir (Goldstein, 2012).

Hollywood günümüzde giderek yabancı seyirciye odaklanmaktadır. Bu bağlamda Rusya, Çin ve Brezilya'daki gençlerin Hollywood filmlerine ilgisi giderek artmaktadır. Warner Bros adlı Hollywood film şirketi "Harry Potter", "Sherlock Holmes" ve "Başlangıç" gibi filmlerle 2010 yılında ABD dişında 2.9 milyar dolar hasılat elde etmiştir. ABD'de dünyanın en büyük ev eğlence sistemlerinden biri olan DVD satışlarının düşmesiyle yabancı gelir kaynklarına daha da bağımlı hale gelmiştir. Bu bağlamda örneğin Kuzey Amerika'da az iş yapan filmler Rusya ve Güney Kore gibi ülkelerde çok daha fazla gişe getirisi elde etmektedir. Rusya, artan genç nüfusu ve sinema salonlarıly Hollywood'un yeni hedef kitlesi durumundadır. 2010 y1lında 160 milyon bilet satılarak ilk defa ülke nüfusundan fazla bilet satılmıştır. 2007'de Rusya'da Amerikan filmleri Rus filmlerinden iki kat daha fazla iş yapmıştır. 2010 yılında Rusya'da sinema sektöründe ithal filmler yerli sinemaya göre 5 kat daha fazla iş yapmıştır. Rus yönetimi de filmleri desteklemek yerine sinema salonlarının sayısının artttırılmasına yönelmiştir. Çin'de sinema gelirleri 2010 yılında 1.5 milyar dolara ulaşmıştır. Çin hükümeti yılda sadece 20 yabancı filmin gösterilmesine izin vermektedir. ABD'de dağıtımcılar gelirden \%50-55 pay alırken, Çindeki Hollywood şirketleri yerel bir dağıtımcıyla anlaşmak zorundadır ve ancak $\% 15$ pay alabilmektedir. Büyük Hollywood stüdyolarının gücü, iyi filmler yapmaktan daha çok filmlerden her şekilde en fazla karı elde etme başarısıdır. Bunu yaparken son derece güçlü pazarlama stratejileri ve yabancı film zevklerine uyum sağlama ve kendini kabul etttirme becerileridir (Hollywood Goes Global, 2012).

Amerikan filmleri sadece Amerika ve Kanada'da masrafını gidermekte, dolayısıyla uluslararası piyasada sırf kar etme güdüsüyle satılmaktadır. Bundan dolayı da yurtdışına filmler daha ucuza satılmaktadır. Bu nedenle mesela Arjantin gibi bir ülkede Arjantin filmlerinin Amerikan filmlerinden daha az şansı olmasının nedeni, gösterim için satış fiyatları 
Amerikan filmlerinden daha pahalı olmasıdır.Bu Hollywood tarafindan uluslararası rekabeti zayıflatmak için kullanılan stratejik bir yöntemdir. Bu stratejinin başka bir boyutunda da Avrupalı yönetmenlerin Hollywood'da film çekmelerinin sağlanması da bulunmaktadır.

Özellikle 2. Dünya Savaşı'ndan sonra yabancı piyasalar Hollywood için çok önem kazanmıştır. 60'larda yabancı piyasadan kazanılanlar bütün gelirin yarısıydı. O tarihten beri yabancı ve ulusal piyasalardan kazanılan miktar az çok aynıdır. Hollywood'da bunun yanı sıra yabancı starları Amerika'ya getirmek yerine, Amerikan yapımlarının yurtdışında çekilmesi gündeme geldi (Maltby, 1997, s.69).

2010 yılında, en az 20 milyon sinema biletinin satıldığı ülkeler ve sinemaları üzerine yapılan bir çalışmada sayısal verileri European Audiovisual Observatory adlı kuruluştan alınmıştır. İlk sırada 2.9 milyar bilet ile Hindistan yer almaktadır ve yerli film seyircisi \%92'dir. ABD 1.3 milyar biletle ikinci sıradadır ve ABD filmlerinin seyircisi de yaklaşık \%92'dir. Çin 217 milyon seyirci ve $\% 57$ yerli sinema seyircisi ile 3.sıradadır. Fransa 200 milyon seyirci ile Avrupa'nın en çok izleyicisi olan ve dünyada en çok Avrupa filmleri gösterilen ülkesidir (\%50.2). İngiltere'deki 173 milyon izleyicinin \%77'si (133 milyon seyirci) Hollywood filmlerine gitmektedir. Almanya ve Rusya yaklaşık 140-145 milyon izleyici ve \%60-65 Hollywood egemenliği rakamsal birliktelik göstermektedir. Türkiye 31 ülkelik listede 37 milyon seyirci ile 20.sırada yer alırken Hollywood egemenliğinin (\%42) en az olduğu beşinci ülkedir. Listedeki 24 ülkede Hollywood egemenliği \%50'den fazladır. Türkiye ayrıca yaklaşık \%51 yerli film izleyicisi ile Hindistan, Çin, Japonya ve Mısır'dan sonra 5.sıradadır. Kısacası Türkiye Hollywood filmlerinden daha çok kendi ulusal filmlerine ilgi gösteren az sayıdaki ülkelerden biridir. Aynı çalışmada Mısır sinemasının Arap ve Müslüman ülkelerdeki etkisine rağmen Türkiye'nin, Türkçe'nin çok yaygın bir dil olmamasından dolayı çevre ülkelerde etkili olmadığına vurgu yapmaktadır (World Domination, 2013).

\section{TÜRK SINNEMA ENDÜSTRİSI}

Türkiye'de, 1960'larda ve 1970'lerde İstanbul'da sinemalar yapımcı şirketler tarafindan paylaşılırken Anadolu'da ise bölge işletmeciliği söz konusuydu.Yapımcıların görevlendirdikleri kişiler filmleri dağıtırlardı. Bilet satışından \%50 komisyon alınırken, işletmeciler de film şirketlerine avanslar ve senetler vererek gösterim gelirinden \%40-60 pay alırlardı. Bununla birlikte yapımcı şirketlere sezon öncesi film siparişi verilirdi. Aynı dönemlerde yabancı film ithalinde çeşitli engeller getirilirken, yabancı filmlere $\% 70$ vergi uygulamasıyla Türk sineması korunuyordu (Erus, 2007,s.8).

1990'lardaki UIP-WB hakimiyeti pazar payı ve dağıtılan Türk filmi bağlamında 2000'lerde Özen Film'e geçmişir. Türk filmi sayısı arttıkça dağıtılan Türk filmi sayısı da artmıştır. UIPWB \%75 iken Özen Film \%25. 2000'lerde \%50 ABD \%34 Özen Film. Yerli filmlerin pay1 1984 'te \%53'ten, 1989'da \%34'e, 1994'te \%16'ya inmiştir (Erus, 2007,s.10).

Türk sinemasının ticari anlamda yükselişinin yanı sıra uluslararası arthouse sinema (sanat sineması) alanında yükseliş söz konusudur. Uluslararası dağıtımda Londra Türk Filmleri Festivali gibi etkinlikler artmaktadır. Nuri Bilge Ceylan, Cannes Film Festivalinde çeşitli ödüller alırken, Semih Kaplanoğlu'nun "Bal” adlı filmle 2010 yılında Berlin Film Festivalinde Altın Ayı ödülü almıştır. Bununla birlikte gişe başarısı sadece Türkiye sınırlarında kalmakta, Mısır sineması gibi Arap diasporasında herhangi bir ticari başarı yaşanamamaktadır. Almanya'da Türk nüfusun yoğunluğuna ve Fatih Akın gibi sinemacılara ve İngiltere'deki Türk topluluğuna rağmen popüler Türk filmleri burada fazla iş yapmamaktadır. Türkiye İslam dünyası içinde en çok kar getiren sinema olarak göze çarpmaktadır. 2010 yılında 193 milyon dolar gişe geliri elde edilmiştir. Aynı yıl Mısır'da sadece 20 milyon dolarlık bir gelir söz konusudur. Yeşilçam döneminde yarı amatör ve fantastik denemelerle Hollywood'dan etkilenmiştir. Günümüzde teknik ve finansal anlamda imkanlar daha fazladır ve Hollywoodvari yaklaşımlar bulunmaktadır (Hoad, 2011). 
2005 yılından 2011'e dek 30 Türk filmi farklı dünya festivallerinde (Cannes, Berlin, Venedik vb.) ödül kazanmıştır. Bu rakam nicel olduğu kadar nitelik açısından da Türk filmlerinin başarısını göstermektedir. Türlere bakıldığında $\% 93$ dram ve melodram $\% 7$ komedi kara mizah ve dram ön plana çıkmaktadır. Temalara bakıldığında ise; köyde banliyöde genç ve çocuk konusu $\% 27$, sıradan insanlar $\% 20$, aşk ve çeşitl ilişkiler $\% 23$, diğer $\% 27$ oranda iken ve siyasa, sosyal meseleler ise sadece $\% 3$ oranında işlenmektedir. Mekan olarak kent \%13 ile en az tercih edilen mekandır. \%27 tercih kıyı mahalle, köy, kır doğa ise \%23, kasaba, küçük şehir \%20 ve diğer mekanlar \%17 oranında tercih edilemektedir. Oyuncu seçiminde \%56 oranda tanınmamış oyuncular söz konusudur. Sinema starı oranı $\% 17$, TV starı $\% 10$ ve diğer oyuncu oranı $\% 17$ 'dir. Özgün nitelik açısından bakıldığında $\% 30$ belgesel nitelikli, fotoğraf estetiği ön planda olan $\% 27$, tür filmi $\% 20$ ve deneysel ve klasik anlatı $\% 13$ oranda işlenmektedir. (Tanrı̈ver, 2011, s.88-91).

Türk yapım şirketleri son dönemlerde ortak yapım filmler ve diziler için, Yunanistan İtalya, Hindistan ve Rusya gibi ülkeler ile çalışmaktadır. Yasal düzenlemeler ile yürürlükteki mevzuat ve teşviklerden yabancı film şirketleri de yararlanmaya başladı. Filmin konusu ve senaryosu gerektirdiği takdirde ortak yapıma katılmayan bir ülkede dış veya iç mekanlarda çekimlere izin verilmektedir. Bollywood-Yeşilçam ortaklığı kapsamında "Anna the Super Rockstar" filminin çekimleri Pamukkale, Peri Bacaları ve İstanbul'da yapıldı. Bazı bölümlerin İran, Yunanistan, İspanya ve Kanada'da çekilmesi planmaktadır. Bütçesi yaklaşık 2 milyon dolar kadardır (Önür, 2012).

Türk-Hint ortak yapımı 'Anna-The Super Rockstar' adlı filmin yapımcılığı Evrensel Medya Grup ile Rakhshan Movies Network tarafindan yapacağı ve sadece prodüksiyonu 3 milyon dolara mal olacacă̆ , daha çekilmeden Türkiye'ye 30 milyon turizm geliri sağladığı haberleri Türk basınında yer almıştır. Polisiye ve aşk temalarının iç içe geçtiği filmin bazı sahneleri Pamukkale, Nemrut Dağı, Peribacaları ve İstanbul'da çekileceği ve filmin Kasım 2012'de Kuzey ve Güney Kore, Çin, Arap yarımadası ve Avrupa ülkelerinde aynı anda izleyici ile buluşacağı bilgisi de bir çok basın organında yer almıştır. (The Super Rockstar, 2012). Söz konusu filmle ilgili 2012 yılında yoğun bir medya tanıtımı yapılmasına rağmen, bu makalenin bitirildiği dönem içinde filmle ilgili başka bir bilgiye ulaşılamamıştır.

Türk sinemasının yurtdışında tanıtımı ile ilgili bir diğer gelişme de 2013 yılının ilk aylarında Pekin'de düzenlenecek bir etkinlikte Türk filmlerinin gösterilmesidir. Film Yapımcıları Meslek Birliği Koordinatörü Ayşe Sönmez, Çinli’lerin Türk fillmlerine ilgi göstermesinden ötürü Pekin Film Festivali'ne bir Türk filmleri panoraması yaptıklarını ifade ederken, Uzakdoğu'da romantik ve aksiyon türlerindeki filmlerin daha çok sevildiğini vurgulamaktadır. Sönmez ayrıca, Türkiye'deki oyuncuların ve yazılan senaryoların artık daha dikkat çekecek boyuta ulaştığını dile getirermektedir. 2012 yılında Bağımsız Sundance Film Festivali'nde dramatik dalda Dünya Sineması Jüri Özel Ödülü'ne layık görülen Raşit Çelikezer'in yazıp yönettiği "Can", Ömer Faruk Sorak'ın yönettiği "Aşk Tesadüfleri Sever", Hasan Tolga Pulat'ın yönettiği "Güzel Günler Göreceğiz", Ahmet Haluk Ünal'ın yönettiği "Saklı Hayatlar" ve Yeşim Sezgin'in yönettiği "Çanakkale 1915" Çinlilerle buluşacak filmler arasında yer almaktadır (Türk Filmleri, 2013)

2008 yılında düzenlenen, 45. Uluslararası Antalya Film Festivalinde, festivalin bir anlamda küresel kapısı olan 4. Ulusararası Avrasya Film Festivali de düzenlendi. Aynı zamanda 3.Avrasya Film Market etkinliği de gerçekleştirildi. Bavaria Film International, HBO Central Europe, Joint Entertainment, Kinowelt International, Maximum Films, Studio Canal gibi birçok uluslarası film şirketi olmak üzere 55 ülkeden 300 kadar yönetici katıldı. Antalya Film Festivali sonrasında başlayan Avrasya Yapım Platformuna Yeni Zellanda, Tayvan, Çin, Fransa, Almanya ve Türkiyeden yapımcılar katıldı. Bu etkinlikte düşük bütçeli ortak yapımlar için görüşmeler yapılırken büyük bütçeli filmlerin Türkiye'de çekilmesi için anlaşmalar yapılmıştır (Turkish Film Bazaar, 2013). 
UNIC (Uluslararası Sinemalar Birliği) Kıdemli Başkan Yardımcısı Phil Clapp, Avrupa'da sinema endüstrisinin en hızlı büyüdüğü ülkenin Türkiye olduğunu belirtmektedir. Tüm Avrupa sinemalarını çatısı altında bulunduran UNIC 2013 yılının ilk toplantısını bütün üyelerinin katılımıyla İstanbul'da gerçekleştirdi. Avrupa'da sinema endüstrisinin en çok Rusya'da daha sonra da Türkiye'de büyüdüğü bilgisini veren Clapp, tüm Türkiye'de bir yılda 45 milyon civarında bilet satıldığını belirtirken, bu sayının kısa sürede iki katına çıkacağını iddia etmektedir. Böylece kişi başına 0.6 sinema biletin düştüğü Türkiye'de pazarın da iki kat büyümesi anlamına gelmektedir (Cengiz, 2013).

Sinema dağıtım zincirlerinden MARS Entertainment'ın ortaklarından Muzaffer Yıldırım, Türkiye'de dünya ile aynı zamanda filmlerin vizyona girememe nedenlerinden birinin hâlâ makara film kullanılması olduğunu ifade etmektedir. Mars Entertainment bünyesindeki sinemalarda dijitalleşme oranının yüzde 26 olduğunu belirten Yıldırım, dünya ile aynı anda 15-20 dijital film gösterilebildiğini, 40 milyon dolarlık dijitalleşmeden sonra bu sayının 80 filme çıkacağını iddia etmektedir. 2012 Avrupa Yerel Film Pazarı ile ilgili rakamalara bakıldığında şöyle bir tablo ile karşılaşmaktayız: Yerel filmlerin izlenme oranları Türkiye'de $\% 50$, Fransa'da \%42, İtalya'da \%38, İngiltere'de \%36'dır. Satılan bilet sayısına bakıldığında ise; Fransa'da 204 milyon, İngiltere'de 172 milyon, Rusya'da 168 milyon, Almanya 135 milyon ve Türkiye 44 milyon adettir. Sinema hasılatında Fransa ve İngiltere 1.3 milyar Euro ile önde giderken, Almanya 1 milyar Euro ve Rusya 962 milyon Euro onları takip etmektedir. Türkiye ise184 milyon Euro ile arka sıralarda yer almaktadır (Cengiz, 2013).

2010 yılında, Zeynep Şantırcıoğlu ve Alex Sutherland adlı iki yapımcı tarafindan İstanbul'da kurulan AZ Celtic Films kısa sürede uluslararası projeler imza attılar. 2013 Oscar Töreni'nde En İyi Film Oscar'ı alan Argo filminin bazı bölümleri İstanbul'da çekilmiştir. AZ Celtic Films Londra'da "Argo" için Warner Bros. yöneticileriyle masaya oturup onları Türkiye'nin film çekilebilecek güvenli bir mekân olduğuna ikna etmek için çaba harcamış ve filmin bazı bölümleri İstanbul'da çekilmiştir. Şirket yöneticileri Kültür Bakanlığı'nın prodüksiyon şirketlerine destek olduğuna ama yabancı filmlerin Türkiye'ye gelmeye devam etmesi için daha fazlasına, devlet teşvikine ihtiyaç olduğunu vurgulamaktadır. Macaristan, Güney Afrika gibi Türkiye'ye rakip ülkelerde yabancı filmlere devlet teşvik sunmakta ve bu da yapımcıya çekici gelmektedir. Şantıroğlu ve Sutherland'e göre bu sektörün ülke tanıtımına ve ekonomisine katkı potansiyeli çok büyüktür. Örneğin geçtiğimiz günlerde Kolombiya yabanc1 filmlere yüzde 40 devlet teşviki sağlayacağını duyurmuştır. Yapımcılar ayrıca Türkiye'de çekimler için daha fazla platolara, stüdyolara, eleman yetiştiren okullara ve ekipman sağlayan şirketlere gereksinim olduğunu belirtmektedirler. Büyük yabancı filmlerin Türkiye'ye gelmesi için daha organize olunması ve mali anlamda onlara kolaylık sağlanması gerekirken, hâlâ bu konuda uygun bir altyapı bulunmamaktadır. Şantırcıoğlu ve Sutherland ayrıca katkıda bulundukları "Tinker Tailor Soldier Spy" adlı film olduğunu, filmde İstanbul'un beklenildiği gibi görünmediğini ve bunun kesinlikle yönetmenin başarısı olduğunu ifade etmektedir. Onlara göre yönetmen, başka bir İstanbul göstermek istedi ve bunu da başarmış oldu. Şirketin "The Two Faces of January" dahil olmak üzere çalıştı̆̆ filmlerden hiçbiri için klişe mekânlarda klişe çekimler yapılmamıştır. Son yaptıkları üç filmin de dönem işi olmasının da avantaj1 olduğu kaçınılmazdır. "Tinker Tailor Soldier Spy" 1979'da, "Argo" 1974'te, "The Two Faces of January" ise 1963'te geçmekteydi (Vural, 2013).

Sonuç olarak, Türk sineması ülkedeki politik ve kültürel dönüşümü yansıtmaktadır. Filmlerde çoğunlukla toplumsal cinsiyet, erkek egemen toplum ele alınmakta ve kültürel bellek işlenmektr. Son 10 yılda yönetmenler modernite ile gelenek, alışanlıklar cinsel kimlik, erkek egemen ideoloji arasındaki mücadele yansıtılmaktadır. Böylece Türk sineması ülkedeki kültürel değişimi, karşıtlıkları ve Türk kültür tarihinin melez anlatımlarını ele almaktadır. Türk sinemasının yabancı seyirciler tarafından ticari açıdan çok ilgi çekmemesinin bu yerel sorunlar ve konular olduğu ileri sürülmektedir (Berlinski, 2009). 


\section{SONUÇ}

Son 20-30 yılda dünyadaki siyasi, kültürel, ekonomik ve teknolojik gelişmeler, bir çok sanat dalını derinden etkilemiştir. Küreselleşme olgusu da bu gelişme ve değişimlerin bir sonucu olarak gündeme gelen ve sıkça tartışılan bir olgusur. Büyük kitleleri etkileyen ve astronomik ticari getirisi olan sinema ve onunla bağlantılı endüstrisi de küreselleşmenin ilgi alanındadır. Bu bağlamda başta Amerikan sinemasının temsil eden Hollywood ve diğer gelişmiş ülkeler sinemayı hem bir propaganda aracı hem de ticari bir alan olarak ele almaktadır.

Sinema tarihi incelendiğinde küresel anlamda en güçlü ülkeler arasında Hollywood yani Amerikan sinemasının başı çektiği görülür. Güçlü bir endüstriye sahip Hollywood sineması yaklaşık 100 yıldan beri dünyanın bir çok ülkesinde milyarlarca kişiyi etkilemiştir. $\mathrm{Bu}$ başarının nedenleri ekonomik ve teknolojik üstünlüğün yanı sıra son derece etkin ve yaygın halkla ilişkiler ve pazarlama çalışmalarının büyük katkısı vardır. Hollywood'un ayrıca dünyadaki bir çok sinemacıyı bünyesine katan yapısı ve Amerikan kültürünün sinema yoluyla milyarlarca kişiyi etkilemesi de, bu ülke ve sinemasını en büyük küresel güçlerden biri haline getirmektedir.

Türk sineması son yıllarda ticari ve sanatsal anlamda yurtiçinde ve yurtdışında çeşitli başarılar elde etmiştir. 1980'lerdeki ve 1990'lardaki göreceli kriz ve gerileme dönemi sonrası yaşanan geçiş döneminin ardından günümüzde Türk sineması uluslararası alanda tartışılır ve üzerinde akademik çalışmalar hazırlanan bir duruma gelmiştir. Türk sineması bu bağlamda küresel pazarda ilerleme gösteren, tanınan, ödüller alan bir sinema olarak tanımlanabilirken, teknik, ekonomik, kültürel ve sosyolojik gibi bir çok nedenlerden dolayı dünyanın önde gelen sinemaları arasında sayılamanaktadır. 100 yıllık süreçte bir türlü gerçekleştirilemeyen endüstrileşme, aşırı yerel konuların ve sorunların ele alınması, sinema salonlarının azlığı, sinema alışkanlığının gereken düzeyde olmaması ve tanıtım ve pazarlama eksikliği gibi olgular Türk sinemasının küresel bir sinema olmaktan daha çok bölgesel ve yerel bir sinema olarak kalmasina neden olmaktadır.

Sonuç olarak Türk sineması; sinema dili, teknik ve estetik değerler ve profesyonel halkla ilişkiler ve pazarlama alanında başarı kazandığı ölçüde, yerelliğini kaybetmeden küresel anlamda önde gelen sinemalar arasına girebilecek potansiyele sahiptir.

\section{KAYNAKLAR}

Berlinski, C. (2009). Turkish Film Renaissance. The National. www.berlinski.com/node/128. Erişim Tarihi: 25.03.2013.

Cengiz, D. (2013). Beyazperdede Yeşilçam hızı. http://www.hurriyet.com.tr/ekonomi/22884517.asp, Erişim Tarihi: 24.03. 2013. Çelik, A. (2011). Kültür Endüstrisi. Literatür Yayıncılık. İstanbul.

Erensoy, Ş. F. (2012). Hollywood'dan Indiewood'a Amerikan Sinemasının Değişimi, İstanbul Kültür Üniversitesi Sosyal Bilimler Enstitüsü Yükseklisans Tezi. İstanbul.

Erus, Z. Ç. (2007). Film Endüstrisi ve Dağıtım: 1990 Sonrası Türk Sinemasında Dağıtım

Sektörü. Selçuk İletişim. 4, 4. s.6-10.

Goldstein, P. (2012). Hollywoods Global Strategy: Made in America, But Not For

Americans. Los Angeles Times, 10 Ocak 2012

http://latimesblogs.latimes.com/movies/2012/01/hollywoods-new-global-strategy-made-inamerica-but-not-for-americans-.html. Erişim Tarihi: 21.03.2013.

Hoad, P. (2011). Playing to Home Audiences keeps Turkey's cinema secene cooking http://m.guardian.co.uk/film/filmblog/2011/nov/22/turkey-cinema-scene-turkish-film. Erişim Tarihi: 21.03 .2013

Hollywood Goes Global: Bigger Abroad (2012). The Economist, 17 Şubat 2012.

www.economist.com/node/18178291/print. Erişim Tarihi: 22.03.2013. 
Maltby, R.(1997). Hollywood Cinema. Blackwell Publishers. İngiltere.

Önür, M.K. (2012). Ortak Yapım Furyası.

www.turkiyegazetesi.com.tr/haberdetay.aspx?NewsID=12066. Erişim Tarihi: 21.03.2013. Tanrı̈ver, H. U. (2011). Türkiye Film Endüstrisini Konumu ve Hedefleri. İTO Yayınları. İstanbul.

The Super Rock Star Filmi 30 Milyon Dolar Turizm Geliri Sağladı. (2012).

http://www.tuyed.org.tr/haberler/the-super-rock-star-filmi-30-milyon-dolar-turizm-gelirisalad.html. Erişim Tarihi: 21.03.2013.

Turkish Film Bazaar Mixes star power\&sales. (2008).

www.thefreelibrary.com/Turkish+film+bazaar+mixes + star+power+\% $\% 26+$ sales Erişim Tarihi: 21.03.2013

Türk Filmleri Çin Yolcusu (2013). http://www.ilkekran.com/haber/turk-filmleri-cin-yolcusu. Erişim Tarihi: 21.03.2013.

Vural, S. (2013). Ben Affleck bizimle yeniden çalışmak istiyor.

http://www.hurriyet.com.tr/magazin/magazinhatti/22887058.asp. Erişim Tarihi: 25.03.2013.

Whipp, G. (2011a). Hollywood tailoring movies for overseas audiences.

http://beta.news.yahoo.com/ hollywood-tailoring-movies-overseas-audiences-1300325.

Erişim Tarihi: 18.05.2011.

Whipp, G. (2011b). Studios try to lessen what's lost in translation.

http://us.mc1124.mail.yahoo.com/mc/showMessage?sMid=2\& filterBy=\&.rand=4345 Erişim Tarihi: 25.07.2011.

World Domination by box office cinema admissions (2011).

http://greenash.net.au/thoughts/2011/07/world-domination-by-box-office-cinema. Erişim

Tarihi: 21.03.2013. 